\title{
A $\mathrm{pH}$ signaling mechanism involved in the spatial distribution of calcium and anion fluxes in ectomycorrhizal roots
}

\author{
Alessandro C. Ramos ${ }^{1}$, Pedro T. Lima ${ }^{1}$, Pedro N. Dias ${ }^{1}$, Maria Catarina M. Kasuya ${ }^{2}$ and \\ José A. Feijó ${ }^{1,3}$ \\ ${ }^{1}$ Instituto Gulbenkian de Ciência, Centro de Biologia do Desenvolvimento, Oeiras, 2780-901, Portugal; ${ }^{2}$ Depto de Microbiologia, Universidade \\ Federal de Viçosa, Viçosa-MG, 36570-000, Brazil; ${ }^{3}$ Depto Biologia Vegetal, Faculdade de Ciências da Universidade de Lisboa, Lisboa, Campo Grande, \\ 1700 , Portugal
}

\section{Summary}

Author for correspondence:

José A. Feijó

Tel: +351214407941

Fax: +351214407970

Email: jfeijo@fc.ul.pt

Received: 2 September 2008

Accepted: 4 September 2008

New Phytologist (2009) 181: 448-462 doi: $10.1111 / j .1469-8137.2008 .02656 . x$

Key words: anion, calcium, ectomycorrhizas, ion-selective vibrating probe, $\mathrm{pH}$ signaling, Pisolithus microcarpus, proton.
- Mycorrhization is a typical example of a host-pathogen symbiotic interaction where the pathogen cell biology and the host immune response coevolved several functional links. Here, the role played by ion fluxes across the root concerning nutrient uptake, osmoregulation, growth and signaling events is addressed. An ion-selective vibrating probe system was used to determine the net fluxes of protons $\left(\mathrm{H}^{+}\right)$, calcium $\left(\mathrm{Ca}^{2+}\right)$ and anions $\left(\mathrm{A}^{-}\right)$along nonmycorrhizal and ectomycorrhizal (ECM) roots of Eucalyptus globulus colonized by Pisolithus sp.

- These data show that, from five root zones analyzed, the main effect of fungal colonization was localized to the elongation zone. Here, strong changes in ion dynamics and rhizosphere acidification capacity were observed. Additionally, ion fluxes exhibited periodic fluctuations.

- To verify whether these fluctuations corresponded to sustained oscillations, continuous wavelet time spectrum analysis was applied and it was determined that $\mathrm{H}^{+}$and $\mathrm{A}^{-}$fluxes from ECM roots had longer periods than nonmycorrhizal roots. By contrast, $\mathrm{Ca}^{2+}$ oscillations were completely abolished following fungal interaction.

- These results are interpreted in the light of a working model in which nutrient uptake and stimulation of growth are mediated by ECM fungi and may be $\mathrm{pH}$ dependent. Furthermore, the variations detected in ECM roots for $\mathrm{H}^{+}$and $\mathrm{A}^{-}$fluxes suggest a main contribution from the plant, while the results obtained for $\mathrm{Ca}^{2+}$ point to a significant involvement of the fungus.

\section{Introduction}

Establishment of an effective ectomycorrhizal symbiosis encompasses a progression of complex and overlapping developmental processes in both the colonizing mycelium and the roots of host trees (Martin et al., 2007).

During mycorrhizal symbiosis, host plants show enhanced growth and increased soil nutrient uptake ability, which are believed to be promoted by the fungal partner (Taylor $\&$ Peterson, 2005). The mechanisms by which this occurs are poorly understood, although a number of anatomical and physiological factors are clearly involved, namely an increase in the absorbing surface area promoted by the extraradical mycelium (Marchner \& Dell, 1994; Gobert \& Plassard, 2002); the synthesis and exudation of organic compounds (Ahonen-Jonnarth et al., 2000; van Scholl et al., 2006) and exoenzymes (Pasqualini et al., 1992; Courty et al., 2006) to the soil in order to solubilize nutrients; and the regulation of host root proteins involved in the nutrient transport across the plasma membrane (PM) (Lei \& Dexheimer, 1988; Javelle et al., 2003; Müller et al., 2007). 
Changing ion fluxes across the root plasma membrane imply alterations of transmembrane electrical potential, contributed by the electrogenic proton $\left(\mathrm{H}^{+}\right)$pumps, which in turn controls ion transport systems (Tazawa, 2003). High $\mathrm{H}^{+}$ATPase activities were found in the PM of external hyphae and sheaths of ectomycorrhizal (ECM) fungi (Lei \& Dexheimer, 1988). This enzyme was also found to be stimulated by external anion concentrations (Churchill \& Sze, 1984; Ullrich \& Novacky, 1990) and inhibited by $\mathrm{Ca}^{2+}$ (Lino et al., 1998). In this context, an induction in the $\mathrm{NO}_{3}^{-}$uptake has been demonstrated for Pinus pinaster ECM roots (Gobert \& Plassard, 2002; Plassard et al., 2002; Boukcim \& Plassard, 2003; Hawkins et al., 2008). This supports the notion that $\mathrm{H}^{+}$transport, $\mathrm{PM} \mathrm{H} \mathrm{H}^{+}$-ATPase activity and root surface acidification work together to promote $\mathrm{NO}_{3}^{-}$uptake (Ullrich \& Novacky, 1990; Glass et al., 1992; Forde, 2000). Positive effects on ion uptake during mycorrhizal symbiosis have been described for nitrogen, phosphate and some tracer elements such as copper and zinc (Marchner \& Dell, 1994), although previous results for calcium have been limited and difficult to interpret (Bücking et al., 2002). For example, in the root cortex almost $100 \%$ of the cell wall calcium can be easily exchanged for an external ${ }^{44} \mathrm{Ca}$ label (Peterson \& Enstone, 1996; Kuhn et al., 2000). Similarly, studies of nutrient mobilization in ECM symbiosis have been performed by radioisotope coupling with laser microprobe mass analysis (LAMMA), energy-dispersive X-ray spectroscopy (EDXS) and secondary ion mass spectroscopy (SIMS) (Peterson \& Enstone, 1996; Bücking \& Heyser, 2000; Bücking et al., 2007). However, very few detailed studies aiming to determine the regulation of ion dynamics in ECM symbiosis have been carried out.

There is a profound effect of $\mathrm{pH}$ on several biological processes, including nutrient uptake, cell growth and plantmicrobe interactions (Feijó et al., 1999; Felle, 2001; Michard et al., 2008). Recently, we showed that extracellular $\mathrm{H}^{+}$ fluxes are involved in both presymbiotic and symbiotic development of arbuscular mycorrhizal symbiosis (Ramos et al., 2008a,b). By contrast, the possible impact of $\mathrm{pH}$ changes was not yet established for ECM associations. Proton fluxes presumably generated by the $\mathrm{PM} \mathrm{H}^{+}$-ATPase activity can modify the root surface $\mathrm{pH}$ in ways that may trigger, for example, modifications in the availability of free extracellular $\mathrm{Ca}^{2+}$ or anion transport.

As a first step to test the role of ion fluxes in ECM associations, we performed a systematic analysis of the different root ion fluxes in the presence and absence of fungal colonization. We measured these fluxes by means of ion-specific vibrating probes. Major alterations were observed in the growing zone of the root, and are compatible with the notion that $\mathrm{pH}$ modulates nutrient uptake. Furthermore, the major alterations detected in ECM roots for $\mathrm{H}^{+}$and $\mathrm{A}^{-}$seem to be associated with root-specific fluxes, while the results for $\mathrm{Ca}^{2+}$ suggest a significant contribution of the fungus.

\section{Materials and Methods}

\section{Biological material, inoculum production and in vitro synthesis of ectomycorrhizas}

Three agar discs containing mycelium of the ECM gasteromycete Pisolithus microcarpus isolate PT 90A were inoculated onto Petri dishes containing $20 \mathrm{ml}$ of modified MNM (Marx, 1969) medium and incubated for $28 \mathrm{~d}$ at $28^{\circ} \mathrm{C}$. From the resulting colonies, $9 \mathrm{~mm}$ agar discs were cut off from the edge of actively growing colonies. Eucalyptus globulus Labill. seeds were superficially sterilized with $5 \%$ sodium hypochlorite (v/v) for $15 \mathrm{~min}$, rinsed with five changes of sterile water, and plated on modified Clark solution at quarter-strength (Clark, 1975) to which was added $2.9 \mu \mathrm{M}$ thiamine- $\mathrm{HCl}$ and $1 \%$ sucrose in $0.5 \%(\mathrm{w} / \mathrm{v})$ Phytagel (Sigma-Aldrich, Gillingham, UK). The use of Phytagel produced a clear and colorless medium, which is excellent for imaging and ion flux measurement with reduced electrical noise (Ramos et al., 2008a). After $7 \mathrm{~d}$, aseptically germinated seedlings were placed on the edge of 10-d-old ECM fungal mycelium grown on the same medium used for seedlings. These were left for $15 \mathrm{~d}$ in a controlledenvironment growth chamber, with $16 \mathrm{~h}$ of light $\left(26^{\circ} \mathrm{C}\right.$, $350 \mu \mathrm{mol} \mathrm{m}^{-2} \mathrm{~s}^{-1}$ ) and $8 \mathrm{~h}$ of dark, for ectomycorrhiza formation. ECM plants were later transferred to hydroponic conditions in the same solution and growth chamber settings for $10 \mathrm{~d}$. Subsequently, ion fluxes measurements were performed in secondary roots of intact plants. In addition, pieces of root system were washed and samples were subsequently collected for microscopic evaluation of mycorrhizal colonization, as described by Brundrett et al. (1996).

\section{Measurements of $\mathrm{H}^{+}, \mathrm{Ca}^{2+}$ and anion fluxes and} currents using the ion-selective vibrating probe system

A detailed description of the experimental setup of the ionselective vibrating probe technique utilized in this study has been well described (Kochian et al., 1992; Feijó et al., 1999; Shipley \& Feijó, 1999; Zonia et al., 2002; Kunkel et al., 2006; Ramos et al., 2008a). In short, E. globulus plants colonized or not by ECM fungus $P$. microcarpus isolate PT 90A under hydroponic conditions, were placed in plastic Petri dishes $(140 \times 140 \mathrm{~mm})$ filled with $30 \mathrm{ml}$ of modified Clark solution at quarter strength, excepted for $\mathrm{Ca}^{2+}$ measurements, where $100 \mu \mathrm{M} \mathrm{Ca}^{2+}$ was used. Visual Minteq analysis was performed according to Parker et al. (1995) using the ion concentrations of the modified Clark solution applied in this study.

We focused on secondary roots, as they are biologically and physiologically more significant than primary roots for nutrient supply to the plant. The volume occupied by secondary roots in the soil can reach $c$. 30-40\% more than primary ones. Readings were taken in five defined root zones of nonmycorrhizal (control) and mycelium-covered roots: apex (tip), meristematic $(100-150 \mu \mathrm{m})$; elongation $(300-800 \mu \mathrm{m})$; root 
hairs (major presence of these structures); and finally mature zone (posterior to root hair zone).

Ion-specific vibrating microelectrodes were produced as described by Feijó et al. (1999). Micropipettes were pulled from $1.5 \mathrm{~mm}$ borosilicate glass capillaries and treated with dimethyl dichlorosilane (Sigma-Aldrich). After silanization, they were backfilled with a 15-20 mm column of electrolyte $\left(15 \mathrm{~mm} \mathrm{KCl}\right.$ and $40 \mathrm{~mm} \mathrm{KH}_{2} \mathrm{PO}_{4}, \mathrm{pH} 6.0$, for $\mathrm{H}^{+} ; 100 \mathrm{~mm}$ $\mathrm{KCl}$ for anions; $100 \mathrm{mM} \mathrm{CaCl}$ for $\mathrm{Ca}^{2+}$ ) and then frontloaded with a $20-25 \mu \mathrm{m}$ column of the respective ion-selective liquid exchange cocktail (Fluka, Milwaukee, WI, USA). We used $\mathrm{Cl}^{-}$electrodes to measure the anion fluxes given that this electrode has poor selectivity for $\mathrm{Cl}^{-}$under our experimental conditions (Supporting information, Fig. S3a,b). Firstly the measurement of chloride activity in the medium is slightly affected by the presence of other ions (Fig. S3a), but these changes should be expressed below noise level within the microvolt range usually measured on vibrating conditions for cellular fluxes. More importantly, the $\mathrm{Cl}^{-}$electrode calibration with different anions showed that this electrode responds with a Nernstian slope to chloride and nitrate, and while sub-Nernstian to sulfate and phosphate, also exhibits a significant response within the concentrations used in this study (Fig. S3b). Last but not least, the background concentrations in the medium of the individual anions span various orders of magnitude, likewise affecting the signal-to-noise $(\mathrm{S} / \mathrm{N})$ ratio measurement of the fluxes in a way that is inversely proportional to the concentration. Taken together, these considerations make it almost impossible to discriminate the individual activities of every single anion, and therefore we have opted to refer to these fluxes as reflecting the global 'anionic' concentration rather than $\mathrm{Cl}^{-}$ proper fluctuations. The final nutrient composition and bioavailability prediction (Ward et al., 2008) are displayed in Table 1 . An $\mathrm{Ag} / \mathrm{AgCl}$ wire electrode holder (World Precision Instruments, Sarasota, FL, USA) was inserted into the back of the microelectrode and established electrical contact with the bathing solution. The ground electrode was a dry reference (DRIREF-2, World Precision Instruments) that was inserted into the sample bath. The microelectrodes were calibrated at the beginning and end of each experiment using standard solutions covering the experimental range of each ion, in order to obtain a calibration line. Both the slope and intercept of the calibration line were used to calculate the respective ion concentration from the $\mathrm{mV}$ values measured during the experiments.

Inhibition with vanadate $\left(\mathrm{VO}_{4}^{3-}\right)$, gadolinium $\left(\mathrm{GdCl}_{3}\right)$ and 4,4'-diisothiocyanatostilbene-2, $2^{\prime}$-disulfonic acid (DIDS)

Inhibitor treatments were performed in Eucalyptus roots after determination of each ion flux at the elongation zone $(n=5)$. The data acquisition was stopped and the respective inhibitors (Sigma-Aldrich) were added in the Petri dishes with the following concentrations: plasma membrane $\mathrm{H}^{+}$-ATPase

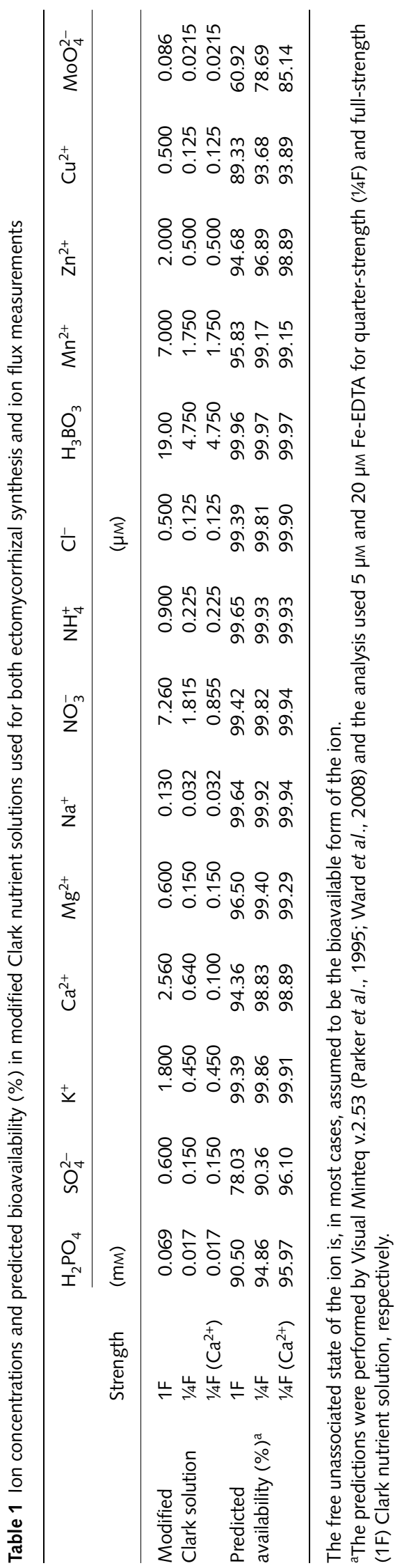

(C) The Authors (2008). 
(100 $\mu \mathrm{M}$ orthovanadate), calcium channels (100 $\mu \mathrm{M}$ gadolinium) and chloride channels ( $50 \mu \mathrm{M}$ DIDS). Five to $10 \mathrm{~min}$ later, a background reference was taken and ion fluxes were again recorded. Interference caused by the inhibitors was controlled for by direct incubation with ionophore-loaded probes. No significant interference of the inhibitors was found to occur for $\mathrm{H}^{+}$and anions. For $\mathrm{Ca}^{2+}$, the interference was more pronounced with high levels of gadolinum, which in the present study was used at lower concentrations $(100 \mu \mathrm{M}$; Fig. S4).

\section{Ion flux oscillation analysis}

Frequency analyses were performed using AutoSignal v1.7 (Systat Software, Inc.). For each set of flux oscillations to be analyzed, a data trend removal was applied, consisting of a linear least-squares fit subtraction to remove the very lowfrequency trend of the data. Two distinct methods were then used to assess the frequency components of the oscillations: Fourier and Wavelet analyses. For Fourier analysis, a fast Fourier transform Radix 2 algorithm was used, ensuring that each data set was a continuous acquisition without breaks and with a constant sampling rate. Peaks were detected by a local maxima detection algorithm and considered relevant according to their significance levels (the higher the significance level, the less likely it is that a detected spectral signal will arise from random noise). Significance levels are given in the Results section. For wavelet analysis, a continuous wavelet timefrequency spectrum was obtained with a noncomplex Morlet wavelet (wave number, 12). A peak-type critical limit was used instead of the traditional confidence levels, as implemented in the software.

\section{Statistical analysis}

All data were analyzed by one-way or two-way ANOVAs in order to compare the mean values (considering 'fungal treatment' and 'root region' as factors), which were validated by convenient residual analyses and, when necessary, combined with Duncan's test for multiple comparison. To compare the control and fungal treatment (Table 2), we applied Student's $t$-test for two independent samples and calculated confidence intervals for the mean difference, in order to guarantee a global $95 \%$ confidence level. The results are expressed as means with respective standard error, and the numbers of repetitions are given in each figure legend. All statistical analyses were conducted using the R program and the level of significance was set up at 5\% (Ihaka \& Gentleman, 1996).

\section{Results}

\section{ECM colonization effects on plant growth parameters}

For ion flux analysis purposes (Fig. 1b), formation of ectomycorrhizas was performed under in vitro conditions (Fig. 1a) in
Table 2 Average values of fungal and plant growth parameters analyzed in nonmycorrhizal (control) or mycorrhizal roots of Eucalyptus globulus colonized by Pisolithus microcarpus (ECM), $10 \mathrm{~d}$ after transplanting to hydroponic conditions $(n=35)$

\begin{tabular}{lcc}
\hline Parameter analyzed & Control & ECM \\
\hline Fungal colonization (\%) & nd & 78.3 \\
Plant heigth (cm) & 14.38 & $17.61^{*}$ \\
Shoot fresh weight (mg per plant) & 33.94 & $45.33^{* *}$ \\
Root fresh weight $(\mathrm{mg}$ per plant) & 12.2 & $15.75^{*}$ \\
Root hair length $(\mu \mathrm{m})$ & 386.52 & $152.39^{* *}$ \\
Root tips $\left(\mathrm{N}^{\circ}\right)$ & 12.00 & 17.00 \\
\hline
\end{tabular}

Significantly differ by Student's $t$-test $\left({ }^{*} P<0.05\right.$; ${ }^{*} P<0.01$;

$\left.{ }^{* * *} P<0.001\right)$. For root tips, $P=0.051$.

nd, not determined.

order to produce E. globulus with a high degree of colonization by $P$. microcarpus isolate $90 \mathrm{~A}$ (Fig. 1c,d). During the experiments, plants presented $78.3 \%$ of ECM root colonization (Table 2; Fig. 1d). In addition, significant and positive effects of ECM colonization were found both on plant height and on shoot and root fresh weights $(P<0.05$; Table 2$)$. No changes in the number of root tips, at the time of the analysis, were detected. A significant decrease in the length of root hairs was found in ECM roots (Table 2). Plant growth was strongly correlated with ionic fluxes as significant Pearson's correlation coefficients were found between $\mathrm{H}^{+}$fluxes and plant growth parameters $(0.78 ; P<0.008)$, root surface $\mathrm{pH}(-0.82$; $P<0.0001)$ and anion fluxes $(-0.59 ; P<0.002)$. Moreover, we also found significant correlation coefficients between root surface $\mathrm{pH}$ and plant growth parameters $(-0.72 ; P<0.0102)$.

\section{$\mathrm{H}^{+}$flux profile and root surface $\mathrm{pH}$}

A differential pattern of $\mathrm{H}^{+}$fluxes was observed along the zones of eucalyptus roots (Fig. 2a). In both nonmycorrhizal and ECM roots, the apex, meristematic and elongation zones were characterized as domains of significant $\mathrm{H}^{+}$efflux. By contrast, root hair and mature zones were characterized as domains of $\mathrm{H}^{+}$influx (Fig. 2a). A sixfold stimulation on $\mathrm{H}^{+}$ effluxes was observed at the elongation zone in the presence of colonizing $P$. microcarpus $(P<0.001)$. As expected, surface $\mathrm{pH}$ values along the root system showed a pattern consistent with the flux profile, and equally affected ECM colonization (Fig. 2b). The two domains described for $\mathrm{H}^{+}$fluxes along the roots corresponded to patches of variable acidity, ranging from 5.56 in the meristematic region to 5.68 in the apex. In ECM roots, significant acidification was observed in the apex, meristematic and, most notably, elongation regions. The lowest $\mathrm{pH}$ value $(<5.4)$ was observed in the elongation zone. In root hairs and mature zones, $\mathrm{pH}$ values were found to be 5.6 and 5.8, respectively. These results support an ECMdriven increase in overall $\mathrm{H}^{+}$influx. All regions showed 

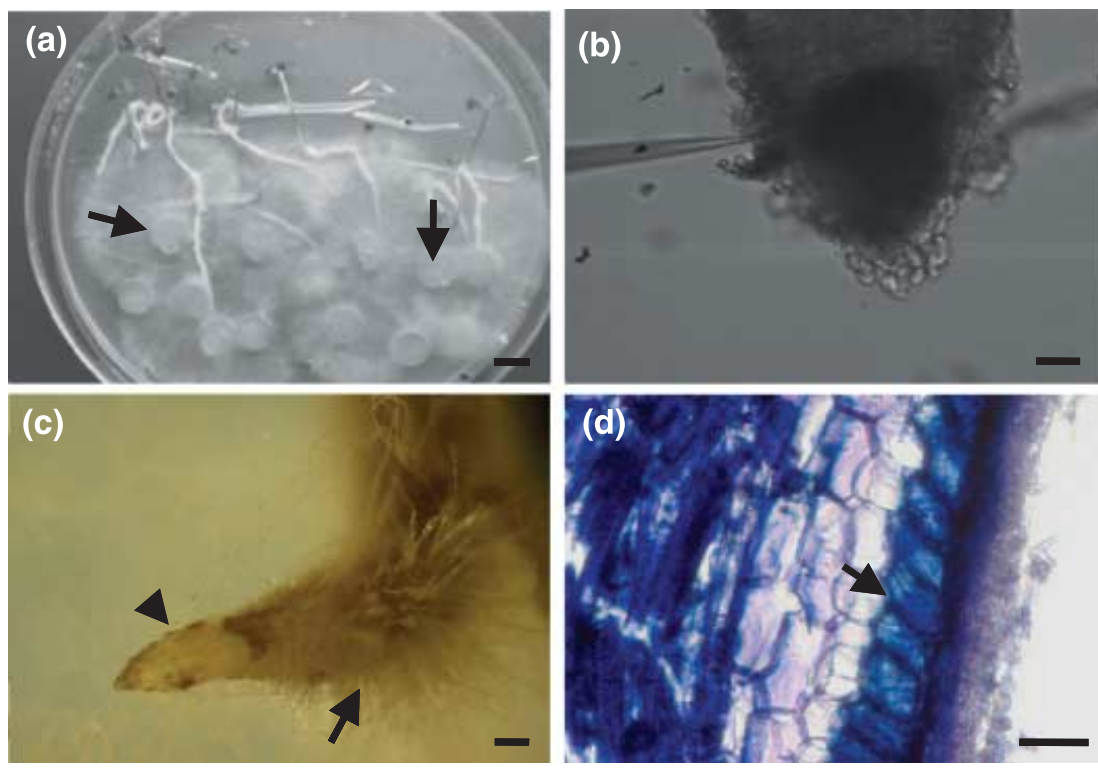

Fig. 1 (a) Ectomycorrhiza formation under in vitro germination conditions of Eucalyptus globulus seedlings and Pisolithus microcarpus before transplanting to hydroponic settings. The arrows show inoculum discs containing MNM medium and fungal mycelium. Bar, $9 \mathrm{~mm}$. (b) Representation of a root apex during measurements with an ion-selective vibrating probe. Bar, $170 \mu \mathrm{m}$. (c) Representation of a lateral root (arrowhead) of $E$. globulus around P. microcarpus mycelium (arrow) under our experimental conditions. Bar, $450 \mu \mathrm{m}$. (d) Cross-section of $E$. globulus roots colonized by Pisolithus microcarpus. The arrow indicates the fungal colonization. Bar, $50 \mu \mathrm{m}$. significant differences in the surface $\mathrm{pH}$ after the establishment of ECM. The global extracellular $\mathrm{pH}$ gradient increased by approx. $0.12 \mathrm{pH}$ units in the control (Me vs Mat) to $0.4 \mathrm{pH}$ units after ECM (Elong vs Mat) (Fig. 2b).

\section{$\mathrm{Ca}^{2+}$ and anion flux profiles}

Interestingly, the patterns of the $\mathrm{Ca}^{2+}$ and anion fluxes in control and ECM roots revealed a quite different scenario. In all zones analyzed, the inoculation of eucalyptus plants induced an inhibition of the magnitude of $\mathrm{Ca}^{2+}$ fluxes (Fig. 3a). Furthermore, an inversion of flux direction (efflux to influx) was observed in the elongation zone. On the other hand, a significant increase of anion influx was observed primarily at the elongation zone $(P<0.001)$ and, to a lesser extent, at the root hair zone $(P<0.01$, Fig. $3 \mathrm{~b})$. The results also showed a significant inhibition of the anion influx at the meristematic zone $(P<0.01)$, but no significant changes were observed at the apex and mature zones (Fig. 3b).

\section{Time-course change of external $\mathrm{Ca}^{2+}$ and anion concentrations}

Analysis of the time-course changes in $\mathrm{Ca}^{2+}$ and anion concentrations in the medium with nonmycorrhizal (control) and ECM roots after a $5 \mathrm{~min}$ exposure to the nutrient medium is presented in Fig. 3(c) and (d). These results indicate that ECM roots were more efficient than the control in taking up $\mathrm{Ca}^{2+}$ ions from the external medium (Fig. 3c). By contrast, control roots seem to take up anions less efficiently than ECM (control change is nonsignificant) (Fig. 3d). This correlates well with the root surface $\mathrm{pH}$ values, since ECM roots showed a superior capacity to acidify the medium compared with the control (Fig. 2b).

\section{Pharmacological assays on $\mathrm{H}^{+}, \mathrm{Ca}^{2+}$ and anion fluxes}

Highly significant changes in the ion fluxes were observed in the root system of $E$. globulus in the presence of $P$. microcarpus ECM fungus, notably in the elongation zone (Figs 2, 3). We further investigated the various fluxes in this region by detailed temporal analysis and pharmacological inference of the putative entities involved in their generation. All fluxes showed a clear oscillatory behavior in the elongation zone, irrespective of the conditions assayed. Changes in the oscillatory components of the ion fluxes were also induced by fungal colonization, mainly in the case of $\mathrm{H}^{+}$and anion fluxes (Fig. 4; wavelet spectral analysis in Fig. 5). The addition of $100 \mu \mathrm{M}$ orthovanadate, a P-type PM H $\mathrm{H}^{+}$-ATPase inhibitor (Bowman, 1982; Bowman et al., 1983), strongly inhibited all effluxes at the elongation zone (Fig. 4a). $\mathrm{Ca}^{2+}$ and anion fluxes were differentially inhibited by $100 \mu \mathrm{M}$ gadolinium and $50 \mu \mathrm{M}$ DIDS, respectively (Fig. 4b,c). Gadolinium $\left(\mathrm{Gd}^{3+}\right)$ is a widely used inhibitor for $\mathrm{Ca}^{2+}$ channels (Yang \& Sachs, 1989; Hedrich et al., 1990; Klüsener et al., 1995; Caldwell et al., 1998; Antoine et al., 2000, 2001) and DIDS is a widely used $\mathrm{Cl}^{-}$blocker (Schroeder et al., 1993; Zonia et al., 2001, 2002; Messerli et al., 2004). Vanadate treatment led to an almost complete blockage of $\mathrm{H}^{+}$fluxes (Fig. 4a, Table 3), and the observed differences between nonmycorrhizal and ECM roots were not significant $(P>0.05)$, suggesting that all effluxes detected were the result of the plasma membrane $\mathrm{H}^{+}$-ATPase activity. Considering the stronger values of $\mathrm{H}^{+}$effluxes in ECM roots and the presence of different $\mathrm{H}^{+}$-ATPase isoforms in the fungal hyphae, presumably with different sensitivities to vanadate, this degree of inhibition came as a surprise. Taken literally, one possible hypothesis is that the major proportions of these fluxes are actually generated by the root epidermis. 
New
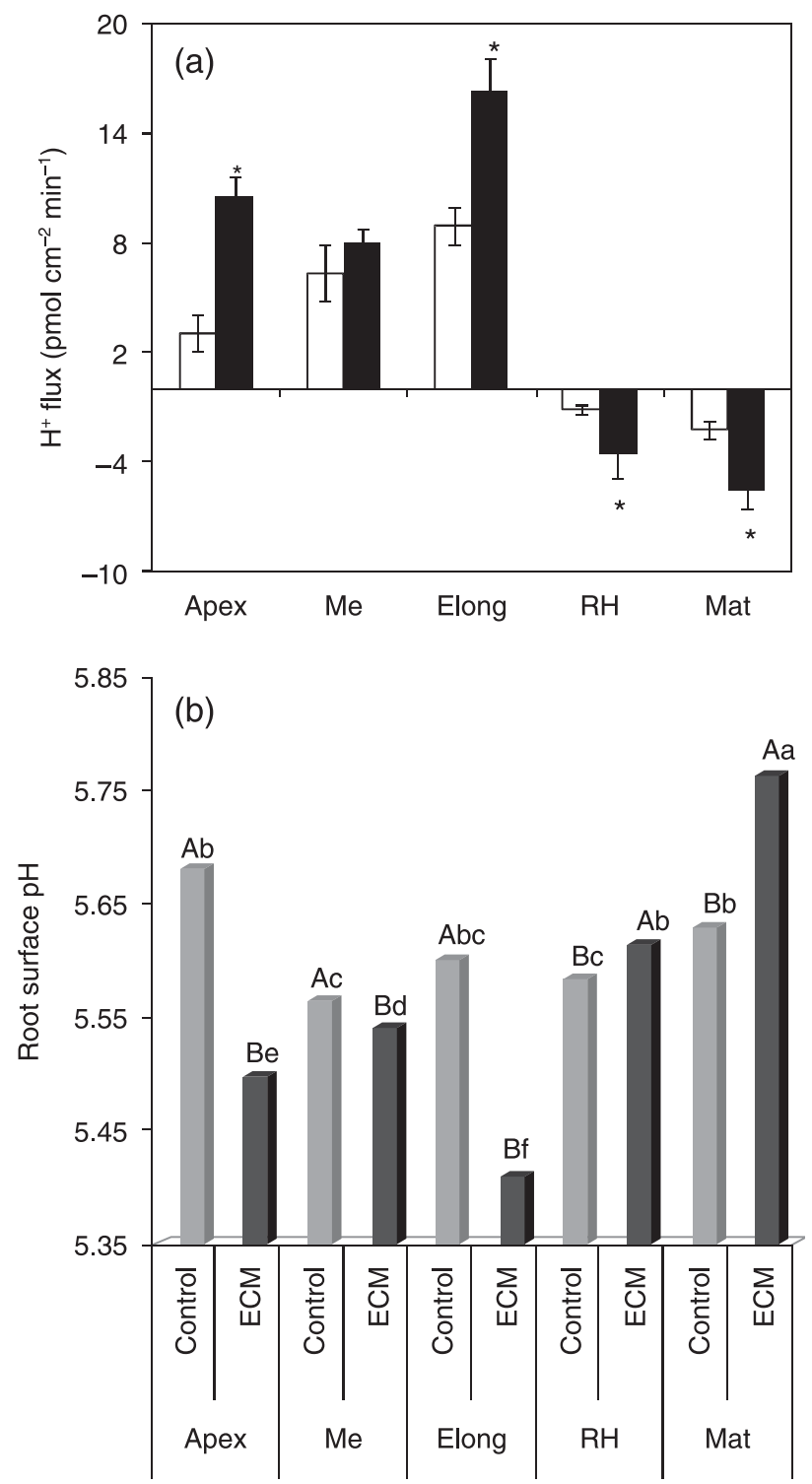

Fig. 2 Proton fluxes (a) and root surface $\mathrm{pH}$ (b) along nonmycorrhizal (control, open bars) and ectomycorrhizal (ECM) roots of Eucalyptus globulus colonized by Pisolithus microcarpus (ECM, closed bars). Apex, meristematic (Me), elongation (Elong), root hairs $(\mathrm{RH})$ and mature (Mat) indicate the zones analyzed. Bars represent the mean values \pm SE of five independent experiments ( ${ }^{*}$ statistical difference at $P<0.01$ ). Negative values correspond to ion influx and positive values to effluxes. For $\mathrm{H}^{+}$fluxes and surface $\mathrm{pH}$, by two-way ANOVA combined with Duncan's test, the results showed that there was significant interaction between fungal treatment and root zones $(P<0.0001)$. For $\mathrm{H}^{+}$fluxes, we found no statistically significant difference with fungal inoculation at the meristematic zone. For $\mathrm{pH}$ data interpretation, bars followed by the same capital letter, in the same root region, are not significantly different by Duncan's test at $P<0.05$. Bars followed by the same lower-case letter, in different root regions, are not significantly different at $P<0.05(n=5)$.
Table 3 Percentage inhibition of $\mathrm{H}^{+}, \mathrm{Ca}^{2+}$ and anion fluxes after the pharmacological assays

\begin{tabular}{llll}
\hline & \multicolumn{2}{l}{$\%$ inhibition } & \\
\cline { 2 - 4 } Treatment & Vanadate & Gadolinium & DIDS \\
\hline Nonmycorrhizal & $97.72^{*}$ & $81.65^{*}$ & $100.00^{*}$ \\
Ectomycorrhizal & 82.60 & 75.41 & 73.83 \\
\hline
\end{tabular}

For $\mathrm{H}^{+}$fluxes, orthovanadate was applied to the final concentration of $100 \mu \mathrm{m}$. For $\mathrm{Ca}^{2+}$ and anion fluxes, $100 \mu \mathrm{m}$ gadolinium and $50 \mu \mathrm{m}$ DIDS, respectively, were applied. $n=5$.

${ }^{*}$ At the same column, the mean values are significantly different by Student's $t$-test at $P<0.01$.

The $\mathrm{Gd}^{3+}$ inhibition of $\mathrm{Ca}^{2+}$ fluxes showed a more complex pattern than that of vanadate on $\mathrm{H}^{+}$fluxes (Fig. 4b; Table 3). As previously mentioned, ECM reverses the efflux to influx in the elongation zone, a result which is difficult to interpret, as it implies a shift in the balance of functional carriers for $\mathrm{Ca}^{2+}$, which are presumably derived from different equilibrium conditions. In the context of ECM, $\mathrm{Gd}^{3+}$ inhibits close to $80 \%$ of the $\mathrm{Ca}^{2+}$ influx, a result consistent with the hypothesis that the majority of $\mathrm{Ca}^{2+}$ is taken up via $\mathrm{Gd}^{3+}$-sensitive channels, some of which could be the result of fungal $\mathrm{Ca}^{2+}$ channels. This conclusion is supported by the observation that there is an almost total inhibition of $\mathrm{Ca}^{2+}$ channels in nonmycorrhizal roots (Figs 4b, 5). However, it should be pointed out that inhibition of an efflux by $\mathrm{Gd}^{3+}$ is not a straightforward interpretable result, and calls for further study.

Anion influxes seem to be proportionally inhibited by DIDS in the same way in both control and ECM roots. This supports the notion that most anion fluxes are root-generated (Fig. 4c; Table 3). Furthermore, it was observed that all inhibitors performed more effectively in control conditions, supporting the hypothesis that in ECM roots there is a greater variety of ion transporters, some of which are refractory to the broadband inhibitors used.

\section{Spectral analysis of the ion flux oscillations}

As illustrated in the traces presented in Fig. 4, most of the continuous time-course measurements of fluxes showed components that were suggestive of sustained periodicity. To the extent that the spectral properties of these temporal variations could enlighten aspects of their regulation, we employed continuous wavelet time-frequency spectrum coupled to Fourier analysis to dissect these properties further. In all cases analyzed, we found evidence for underlying oscillations, sometimes with one single component, and at other times with more than one component (Fig. 5a,c,e). More interestingly, they all showed some degree of modification upon colonization of Eucalyptus roots with the ECM fungus P. microcarpus 

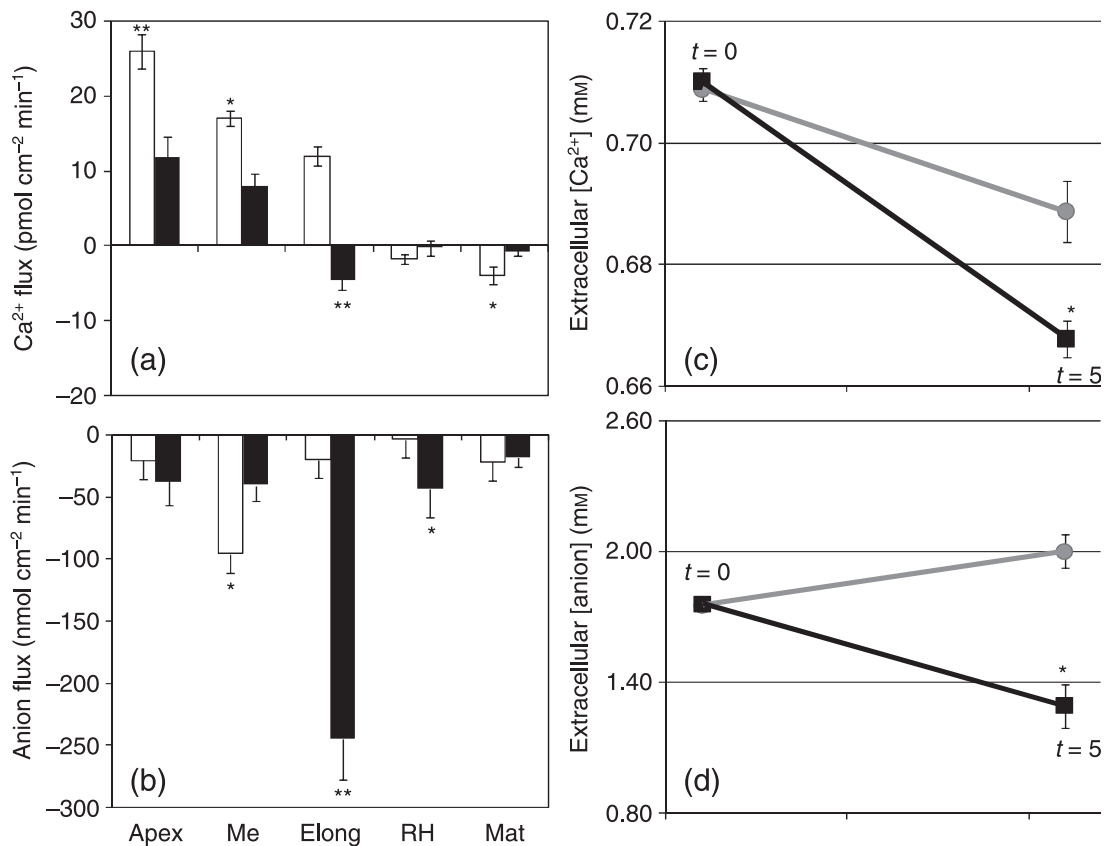

Fig. 3 Fluxes of calcium (a) and anions (b) along nonmycorrhizal (control, open bars) and ectomycorrhizal (ECM) roots of Eucalyptus globulus colonized by Pisolithus microcarpus (closed bars). Apex, meristematic (Me), elongation (Elong), root hairs (RH) and mature (Mat) refer to the root zones analyzed. Negative values correspond to ion influx and positive values to effluxes. Bars represent mean values $\pm S E$ of five independent experiments. (c, d) Fluctuations on external $\mathrm{Ca}^{2+}(\mathrm{c})$ and anion (d) concentrations in nonmycorrhizal (control, circles) and ECM (squares) roots. For uptake analysis, roots were exposed for 5 min to Clark solution containing $0.2 \mathrm{~mm} \mathrm{Ca}^{2+}$ (c) and $1.5 \mathrm{~mm}$ anions (d). Scale bars represent the mean values \pm standard error $(n=5)$. * Means significantly different by Student's $t$-test at $P<0.001$. For $\mathrm{Ca}^{2+}$ and anion fluxes, by two-way ANOVA combined with Duncan's test, the results showed that there were significant interactions between fungal treatment and root zones $(P<0.0001)$. There were no significant effects of fungal inoculation for $\mathrm{Ca}^{2+}$ fluxes at the root hair zone, and for anion fluxes at the apex and mature zones. ${ }^{*}, P<0.01 ;{ }^{*}, P<0.001$.

(Fig. 5b,d,f). Results shown in Fig. 5 reveal that, in the control $\mathrm{H}^{+}$flux oscillations, there is one dominant period of c. $3.1 \mathrm{~min}$, which lengthens to $5.3 \mathrm{~min}$ in the presence of the ECM fungus (Fig. 5a,b). This broadening of the major components of the oscillations were confirmed by Fourier analysis $(P<0.05$; Fig. S1a,b). In addition, no significant oscillations were found in controls without a biological sample (Fig. S2d,e,f).

By contrast, $\mathrm{Ca}^{2+}$ flux oscillations seem to show an opposing trend after ECM (Fig. 5c,d). Firstly, they seem to have two major components in the control condition: a dominant one of c. $5.3 \mathrm{~min}(P<0.01)$ and a second of $c .1 .5 \mathrm{~min}$. However, both disappeared in the presence of the fungus (Fig. $5 \mathrm{c}, \mathrm{d}$ ), giving rise to a number of small periods at the borderline of the $\mathrm{S} / \mathrm{N}$ ratio of the system. The Fourier analysis confirmed these results and showed that some of the high frequencies detected by continuous wavelet time-frequency spectrum analysis were not statistically significant at $P<0.05$ (Fig. S1c,d). Finally, anion fluxes showed a third and different scenario. Control roots had at least one significant oscillation period of c. $0.6 \mathrm{~min}$, thus characterized as being very fast, together with others considered nonsignificant by Fourier analysis at $P<0.05$ (Fig. 5e, S1e). In the presence of the ECM fungus, however, there was a drastic change of behavior, giving rise to a longer period of c. $3.0 \mathrm{~min}$ (Fig. 5e,f, S1f). Fourier analysis revealed the same short period of $0.6 \mathrm{~min}$ in ECM roots as above the level of system noise, but with a much reduced significance. These results demonstrate that the ECM colonization changes the $\mathrm{H}^{+}$and anion flux oscillations, by increasing their periods by approx. double and sixfold, respectively, while for $\mathrm{Ca}^{2+}$ flux the oscillations are completely disrupted in the presence of the fungus. In addition, all ion flux oscillations were fully inhibited by the respective inhibitors such as orthovanadate, gadolinium and DIDS (data not shown).

\section{A dual effect of the external $\mathrm{pH}$ and $\mathrm{Ca}^{2+}$ concentration on extracellular ion fluxes}

In systems showing prominent $\mathrm{pH}$ and $\mathrm{Ca}^{2+}$ dependency, the homeostasis of these ions seems to be closely interrelated. We tested whether this was also the case at the elongation zone, by growing E. globulus roots in medium with three different $\mathrm{Ca}^{2+}$ concentrations $(0,0.5,1 \mathrm{~mm})$ for $5 \mathrm{~d}$, and analyzing the $\mathrm{H}^{+}$ fluxes and root surface $\mathrm{pH}$ after that period (Fig. 6). The results showed that an increase in $\mathrm{Ca}^{2+}$ availability provoked a significant inhibition on the $\mathrm{H}^{+}$effluxes in the root elongation zone (Fig. 6a). Likewise, the root surface $\mathrm{pH}$ increased with the $\mathrm{Ca}^{2+}$ concentration. Also, at $0.5 \mathrm{~mm} \mathrm{Ca}^{2+}$, 
New

Phytologist

(a)

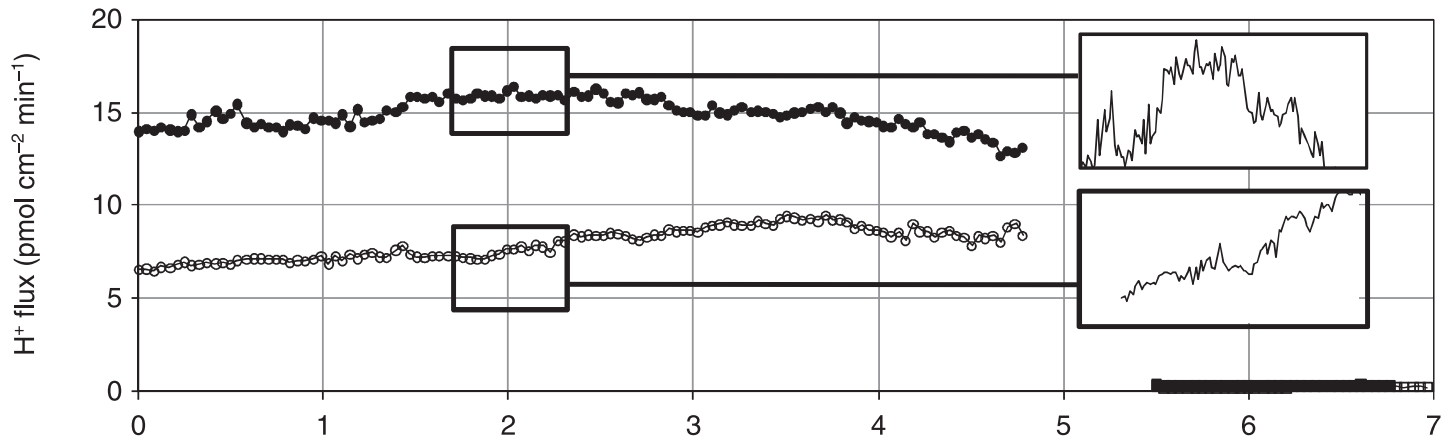

(b)

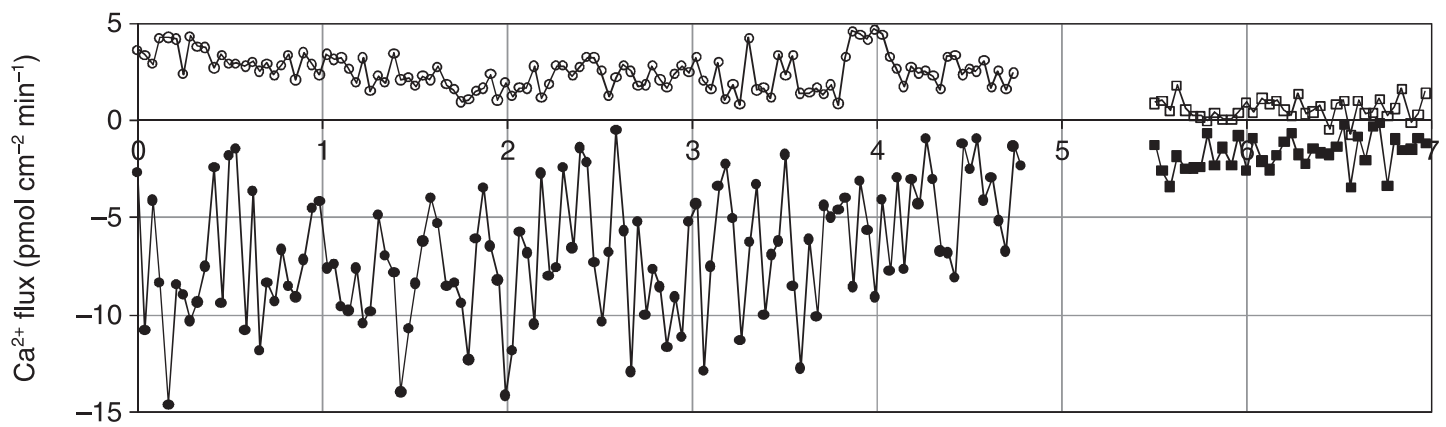

(c)

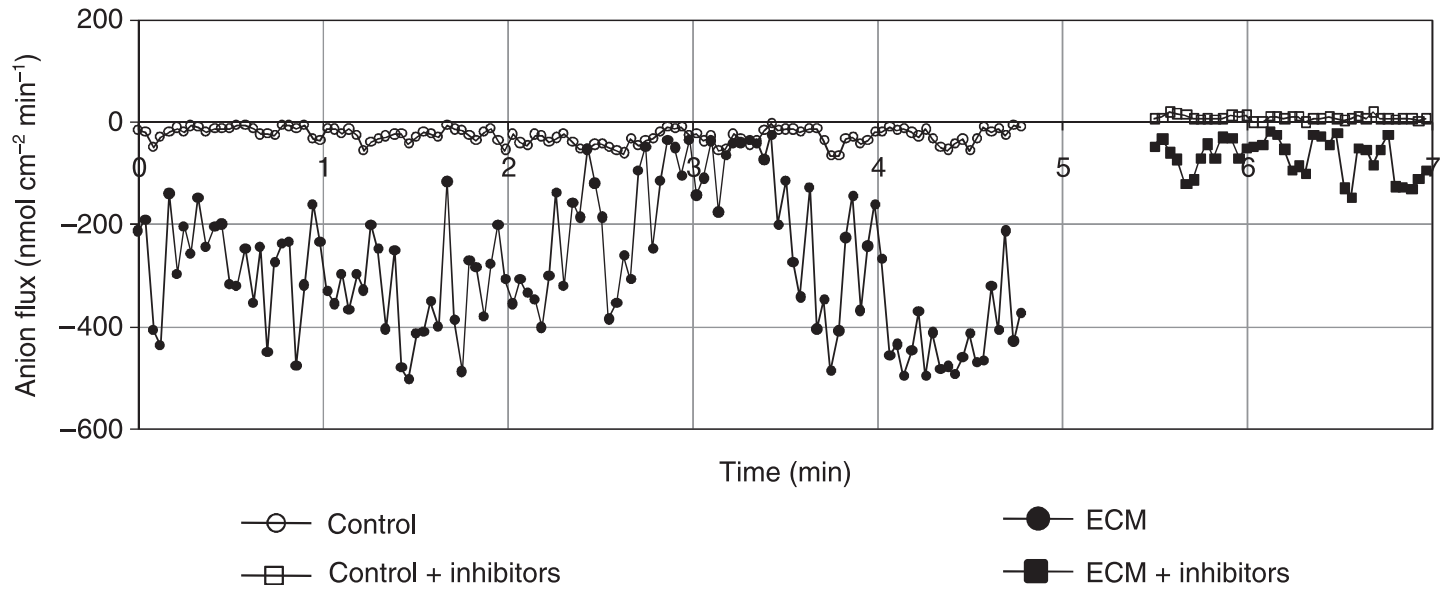

Fig. 4 A representative graphical display of the standard output showing the oscillations of ion fluxes in the elongation zone of nonmycorrhizal (control) or mycorrhizal roots of Eucalyptus globulus colonized by Pisolithus microcarpus (ECM). (a) $\mathrm{H}^{+}$flux oscillations in the absence and presence of $100 \mu \mathrm{m}$ orthovanadate $\left(\mathrm{VO}_{4}^{3-}\right)$. (b) $\mathrm{Ca}^{2+}$ flux oscillations in the absence and presence of $100 \mu \mathrm{M}$ gadolinium $\left(\mathrm{Gd}^{3+}\right)$. (c) Anion flux oscillations in the absence and presence of $50 \mu \mathrm{M} 4,4^{\prime}$-diisothiocyanatostilbene-2,2'-disulfonic acid (DIDS). Negative values correspond to ion influx and the positive values to effluxes.

almost all $\mathrm{H}^{+}$effluxes were inhibited (Fig. 6a). $\mathrm{pH}$ also induced some changes on $\mathrm{Ca}^{2+}$ efflux at the elongation zone, since under acidic conditions $(\mathrm{pH}$ 5.3) there was a significant increase in $\mathrm{Ca}^{2+}$ efflux (Fig. 6b). By contrast, under basic conditions, a significant inversion of the $\mathrm{Ca}^{2+}$ efflux to one of influx was observed, suggesting the presence of a $\mathrm{pH}$-sensitive $\mathrm{Ca}^{2+}$ transport at the elongation zone.

\section{Discussion}

This study presents the novel observation that different Eucalyptus root zones experience a differential modulation in their ion fluxes by the colonization of the ECM fungus P. microcarpus. Our experimental approach was efficient to produce plants with a high degree of fungal colonization at the stage of analysis. Thus, despite the inhibition of root hair growth, positive effects of ECM fungus on plant growth were observed (Table 2). This is a new aspect of hostpathogen interaction during ECM that reveals a potentially important aspect of coevolution between the fungal cell biology and the plant immune system, and one that may open for new paradigms of celll-cell communication through ion signaling pathways. 


\section{Continuous wavelet time-frequency spectrum}
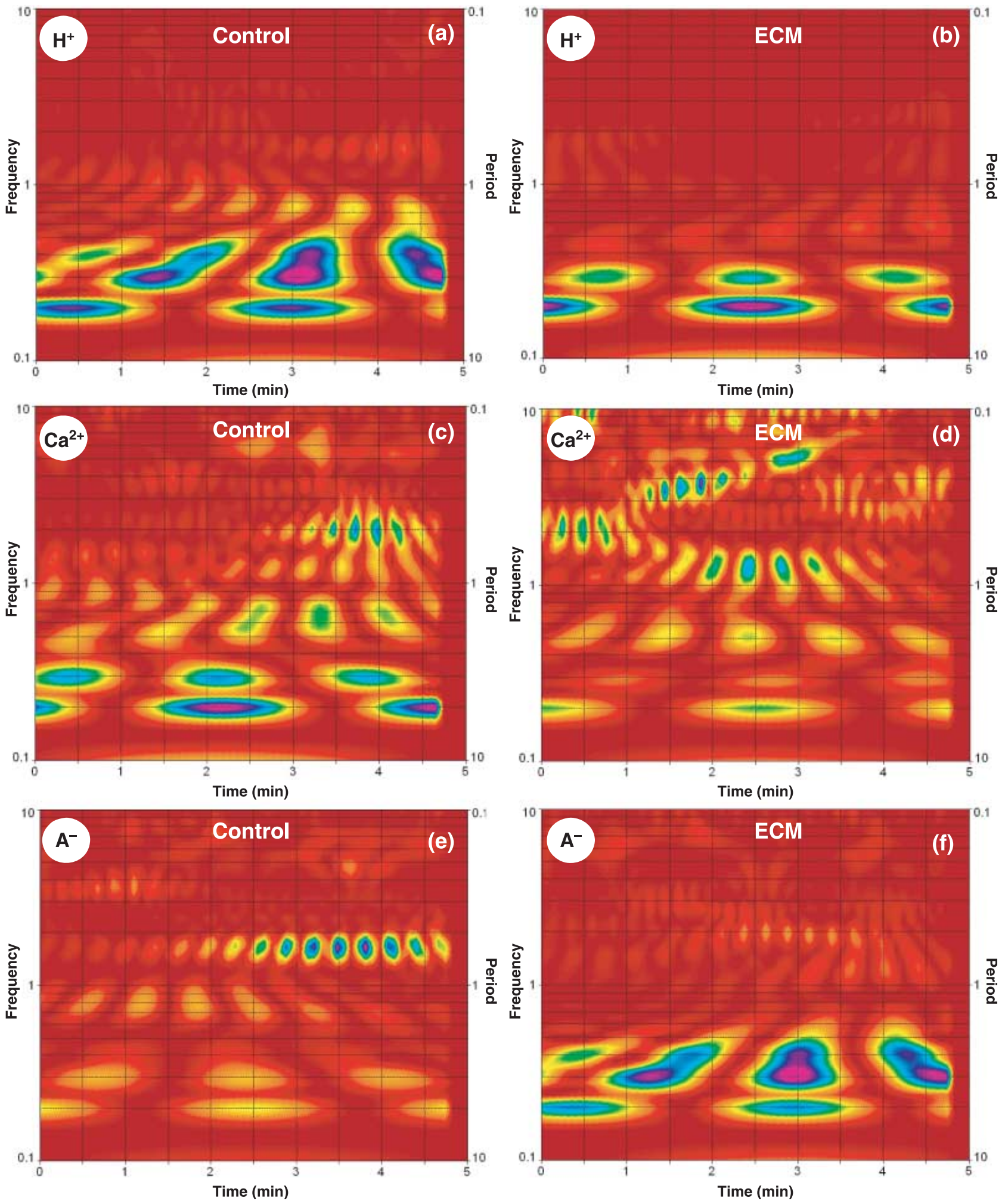

Fig. 5 Continuous wavelet time spectrum analyses of the $\mathrm{H}^{+}(\mathrm{a}, \mathrm{b}), \mathrm{Ca}^{2+}(\mathrm{c}, \mathrm{d})$ and anion flux oscillations in the elongation zone of nonmycorrhizal ( $a, c, e)$ and mycorrhizal roots (ECM) of Eucalyptus globulus colonized by Pisolithus microcarpus (b, d, f), as presented in Fig. 4. The frequencies are represented in $\mathrm{min}^{-1}$ and the periods in min. Wavelet analysis was coupled to Fourier analysis in order to dissect the frequency components, and shows the oscillatory pattern of the ion fluxes. No significant periods of ion fluxes were found in the medium without any biological sample (see also Fig. S2). 
New

Phytologist
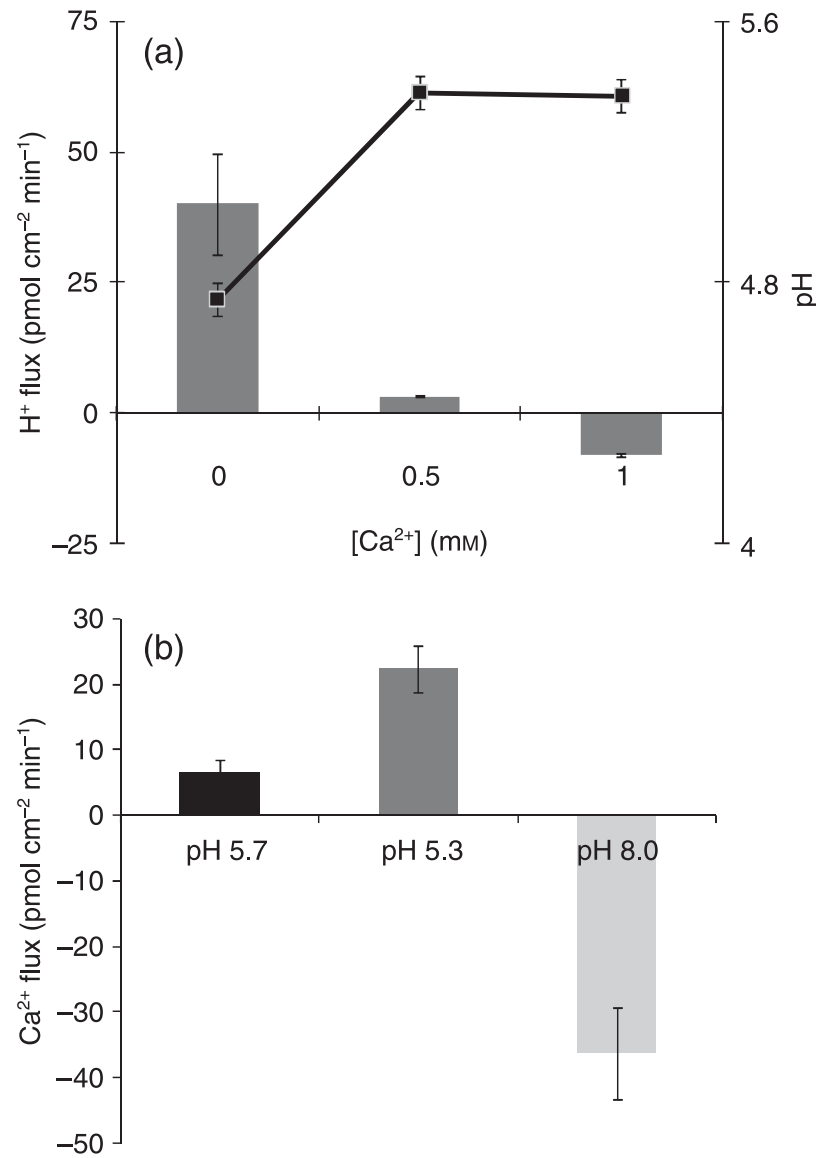

Fig. 6 (a) Extracellular $\mathrm{H}^{+}$fluxes (bars) and root surface $\mathrm{pH}$ values (squares) at the elongation zone of Eucalyptus globulus roots under three calcium concentrations $\left(\mathrm{CaCl}_{2}\right)$. (b) Extracellular $\mathrm{Ca}^{2+}$ fluxes at the elongation zone with three different medium $\mathrm{pH}$ values. In this experiment, $\mathrm{pH} 5.7$ was used as the control, since this value was used for all experiments of this work. The remaining $\mathrm{pH}$ values were obtained by growing roots for $2 \mathrm{~d}$ in the same medium used for ion flux analysis, to which was added $50 \mu \mathrm{M}$ Tris- $\mathrm{HCl}, \mathrm{pH} 5.3$, or $50 \mu \mathrm{M}$ Tris-base, $\mathrm{pH}$ 8.0. The negative values correspond to ion influx and the positive values to effluxes.

The control of root surface $\mathrm{pH}$ in ECM roots by extracellular $\mathrm{H}^{+}$fluxes is linked to $\mathrm{PM} \mathrm{H}^{+}$-ATPase activity

In comparison with control uninfected plants, the highest rates of $\mathrm{H}^{+}$efflux and acidic surface $\mathrm{pH}$ were located at the elongation zones of ECM roots (Fig. 2). These effluxes are dependent on the $\mathrm{PM} \mathrm{H}^{+}$-ATPase, as they were inhibited by $100 \mu \mathrm{M}$ orthovanadate (inhibitor of P-type plasma membrane $\mathrm{H}^{+}$-ATPase), a result which is conceptually sound since the elongation zone is a specialized growing zone (Winch \& Pritchard, 1999). In fact, it has been shown that this zone shows notably higher immunolocalization and higher activity levels of PM $\mathrm{H}^{+}$-ATPase than the apical and meristematic zones (Jahn et al., 1998; Palmgren, 2001; see details in Enriquez-Arredondo et al., 2005). Using immunocytochemical approaches, Lei \& Dexheimer (1988) found strong PM $\mathrm{H}^{+}$-ATPase labeling in root cortical cells of Pinus sylvestrisLaccaria laccata, in external hyphae sheaths and Hartig nets. This localization supports the concept of a coupling mechanism between fungal and host $\mathrm{H}^{+}$pumps in ECM roots (Fig. 2, Table 3). Indeed, it has been demonstrated that for arbuscular mycorrhizal associations, some host $\mathrm{PM} \mathrm{H}^{+}$-ATPase isoforms show increased activity and gene expression after fungal colonization (Ferrol et al., 2002; Ramos et al., 2005; details in Rosewarne et al., 2007).

The $\mathrm{H}^{+}$efflux mediated by the $\mathrm{PM} \mathrm{H}^{+}$-ATPase is important for the regulation of cytoplasmic $\mathrm{pH}$ (Felle, 2001; Palmgren, 2001; Tazawa, 2003) and the activation of cell wall-loosening enzymes and proteins through acidification of the apoplast (Hager, 2003). This effect is closely related to auxin-induced cell growth as proposed by the 'acid-growth theory' by Rayle $\&$ Cleland (1992). This implies that enhanced $\mathrm{H}^{+}$efflux in ECM roots (Fig. 2a) results in an acidification of the apoplastic/ external pH (Fig. 2b). Moloney et al. (1981) demonstrated that $\mathrm{pH}$ changes in the apoplast are crucial for root growth, since acidic buffering conditions act as stimulators whilst neutral or basic $\mathrm{pHs}$ act as inhibitors. Our results clearly show that when the $\mathrm{H}^{+}$flux rate (Fig. 2a) and surface $\mathrm{pH}$ values (Fig. 2b) are combined, highly significant Pearson's correlation coefficients are obtained $(-0.82 ; P<0.0001)$. Other candidates that contribute to the control of extracellular $\mathrm{H}^{+}$flux in ECM are the presence of anions in the growth medium. These are reported to act as stimulators of the $\mathrm{PM} \mathrm{H}^{+}$-ATPase (Churchill \& Sze, 1984; Ullrich \& Novacky, 1990; Glass et al., 1992; Forde, 2000; Garnett et al., 2001). This concept is especially appealing taking into account the observed oscillatory behavior (Figs 5, S1), where the ECM colonization induced changes in the flux oscillations, leading to their increased periods. For $\mathrm{Ca}^{2+}$ flux oscillation, ECM colonization abolished all significant periods observed in control roots (Figs 5b,c, S1). Combined with the reversion from efflux to influx in the elongation zone, this result could be interpreted as showing that the fungus contributes to the majority of the $\mathrm{Ca}^{2+}$ influx through specific channels. These different activities would produce intricate temporal patterns impossible to synchronize on an organized oscillatory pattern. This being the case, the prediction would be that ectomycorrhizal plants should have an improved efficiency of $\mathrm{Ca}^{2+}$ uptake from the soil, a result partly confirmed in Fig. 3(c).

\section{$\mathrm{Ca}^{2+}$ efflux suppression and increase upon $\mathrm{Ca}^{2+}$ uptake in ECM roots}

Calcium has a paradoxical effect on $\mathrm{PM} \mathrm{H}^{+}$-ATPase, as it has been reported to be an inhibitor via a $\mathrm{Ca}^{2+}$-dependent phosphorylation pathway (Lino et al., 1998; Tazawa, 2003) and an activator in guard cells (Assmann et al., 1985). An inhibition of the PM Ca ${ }^{2+}$ influx channels in both animal (Yang \& Sachs, 1989) and plant cells (Allen \& Sanders, 1994; 
Klüsener et al., 1995; Knight et al., 1996; Antoine et al., 2000,2001 ) occurs by the addition of extracellular $\mathrm{Gd}^{3+}$ in a micromolar range. Despite its use for detection of $\mathrm{Ca}^{2+}$ stretch-activated channels (Caldwell et al., 1998), $\mathrm{Gd}^{3+}$ is likely to inhibit other cationic channels as well, because of its relatively broad effect. Our pharmacological analysis suggested that the $\mathrm{Ca}^{2+}$ influx in the elongation zone of ECM roots is the result of the activity of $\mathrm{Gd}^{3+}$-sensitive calcium channels (Figs 3a, 4; Table 3). However, as the $\mathrm{Ca}^{2+}$ effluxes are largely governed by the chemical potential gradient of $\mathrm{Ca}^{2+}$ generated by the PM Ca ${ }^{2+}$-ATPase, we hypothesized that the suppression of effluxes in the control roots could represent an indirect dissipation of the $\mathrm{Ca}^{2+}$ gradient, as promoted by $\mathrm{Gd}^{3+}$ treatment (Fig. 4, Table 3). In addition, similar flux inhibition profiles were obtained by Nemchinov et al. (2008) in Nicotiana benthamiana leaves. The authors proposed a model in which $\mathrm{Gd}^{3+}$-sensitive $\mathrm{Ca}^{2+}$ influxes and $\mathrm{Ca}^{2+}$ pumps are involved in the signal transduction pathways of the hypersensitive response mechanisms (Nemchinov et al., 2008). As a passive $\mathrm{Ca}^{2+}$ efflux from the cell cytosol is thermodynamically improbable (Shabala \& Newman, 2000), an active mechanism must be involved. Two possible mechanisms of $\mathrm{Ca}^{2+}$ efflux might occur, one through $\mathrm{Ca}^{2+}$ release from the cell wall and the other by $\mathrm{Ca}^{2+}$ extrusion via the PM Ca ${ }^{2+}$-ATPase (Lecourieux et al., 2006; Nemchinov et al., 2008). It remains to be determined which of these two mechanisms is responsible for this event to occur. Alternatively, an increase in the activity of $\mathrm{Ca}^{2+}$ influx in ECM roots could reflect an increased cytosolic concentration of this ion. Indeed, it has recently been demonstrated that the exposure of E. globulus root hairs to hypaphorine (an indole alkaloid secreted by $P$. microcarpus) led to an elevation of cytoplasmic $\mathrm{Ca}^{2+}$ concentration (Dauphin et al., 2007). Thus, hypaphorine led to a reduction of the $\mathrm{Ca}^{2+}$ gradient across the plasma membrane, which was correlated with the arrested growth of root hairs (Béguiristain \& Lapeyrie, 1997; Dauphin et al., 2007). These results seem similar to our own observations (Table 2), where root hair length was reduced in ECM roots. Recently, Martin et al. (2008) published the genome of the ECM fungus Laccaria bicolor, in which numerous and diverse $\mathrm{Ca}^{2+}$ channels are found to be encoded (see details at http:// genome.jgi-psf.org/Lacbi1/Lacbi1.home.html). Accordingly, we found ECM roots to have a higher uptake capacity of $\mathrm{Ca}^{2+}$ from the external medium (Fig. 3c). In itself this would not necessarily lead to a major accumulation of $\mathrm{Ca}^{2+}$ in ECM of whole plants, but clearly suggests a higher potential for ion uptake and storage in the cell wall (Peterson \& Enstone, 1996; Kuhn et al., 2000) promoted by the fungus. In ECM associations, such as Suilus bovinus-Pinus sylvestris, an exposure to $\mathrm{Ca}^{2+}$ also led to an accumulation of this ion in the interfacial apoplast in between symbionts and in the fungal sheath (Bücking et al., 2002). Depending on the fungal species, $\mathrm{Ca}^{2+}$ can also accumulate as calcium oxalate in the fungal hyphae (Malajczuk \& Cromack, 1982). In the light of this, calcium dynamics in ECM interactions needs to be more carefully investigated, not just using radioisotopes, but also by means of an integration of techniques such as ion-selective vibrating probes, patch-clamp and imaging analyses.

\section{Activation of anion uptake by ECM fungus}

It is well known that an increase in the root surface concentration of $\mathrm{H}^{+}$generates a proton-motive force, which is necessary to drive the secondary transport of $\mathrm{NO}_{3}^{-}, \mathrm{SO}_{4}^{2+}$, $\mathrm{Cl}^{-}, \mathrm{Ca}^{2+}$ and $\mathrm{K}^{+}$(Portillo, 2000; Palmgren, 2001). Accordingly, we found that the changes in $\mathrm{H}^{+}$efflux attributable to ECM fungal infection in the elongation zone were strictly correlated to the root surface $\mathrm{pH}$ values $(-0.82 ; P<0.0001)$, and, significantly, correlations of root surface concentrations of $\mathrm{H}^{+}$ were found with both $\mathrm{Ca}^{2+}(-0.78, P<0.001)$ and anion fluxes $(0.66 ; P<0.006)$. The correlation between $\mathrm{Ca}^{2+}$ and anions at the elongation zone $(0.99, P<0.001)$ raised the possibility of an activation of anion influx by $\mathrm{Ca}^{2+}$, as demonstrated in other cells (Hedrich et al., 1990). Since plant cells have adapted to low anion concentrations, anion uptake is generally coupled to the electrochemical gradient generated by the $\mathrm{PM} \mathrm{H} \mathrm{H}^{+}$-ATPase activity (Evans et al., 1980; Zimmermann et al., 1994; Garnett et al., 2001). Consequently, ECM roots possess strong anion influxes and $\mathrm{H}^{+}$effluxes primarily at the elongation zone (Fig. 3b). Consistent with this, we observed high $\mathrm{H}^{+}$-ATPase activity in this root zone. It has been reported that this enzyme is stimulated by anions in plant (Churchill et al., 1983; Churchill \& Sze, 1984; Zimmermann etal., 1994) and animal cell membranes (Vieira et al., 1995). The induction of $\mathrm{NO}_{3}^{-}$uptake in $P$. pinaster ECM roots, even at low external concentrations, was previously shown by Gobert \& Plassard (2002). The $\mathrm{H}^{+}$ efflux and consequent root surface acidification are necessary for the $\mathrm{NO}_{3}^{-}$uptake mechanism to operate (Ullrich \& Novacky, 1990; Glass et al., 1992; Forde, 2000), as this occurs via $\mathrm{PM}$ cotransporters $\left(\mathrm{nH}^{+} / \mathrm{NO}_{3}^{-}\right)$(Crawford, 1995). This was already demonstrated for Eucalyptus nitens, where large $\mathrm{H}^{+}$effluxes were found in medium with $\mathrm{NO}_{3}^{-}$. However, $\mathrm{NO}_{3}^{-}$fluxes were quantitatively linked to $\mathrm{H}^{+}$fluxes (Garnett \& Smethurst, 1999; Garnett et al., 2001, 2003). In addition, according to Garnett et al. (2003), negative correlation coefficients can be obtained between $\mathrm{NO}_{3}^{-}$and $\mathrm{H}^{+}$fluxes. Nitrate is thus a strong candidate to be a component of the anion fluxes we observed, but unfortunately the technical limitations of the electrodes used do not warrant a straightforward conclusion in this respect (see the Materials and Methods section and Fig. S3a,b), with chloride probably playing also an important role.

In normal conditions, the maintenance of the electrical membrane potential depends on the $\mathrm{H}^{+}$efflux and influxes of anions and potassium (Felle, 2001; Tazawa, 2003). In ECM symbiosis, fungi have a high capacity to uptake potassium in their external hyphae (Rygiewicz \& Bledsoe, 1984). One 
New

Fig. 7 Proposed model for the $\mathrm{pH}$ signaling mechanism in ectomycorrhizal (ECM) roots and the differential modulation of anion $\left(\mathrm{A}^{-}\right)$ and calcium $\left(\mathrm{Ca}^{2+}\right)$ uptake.

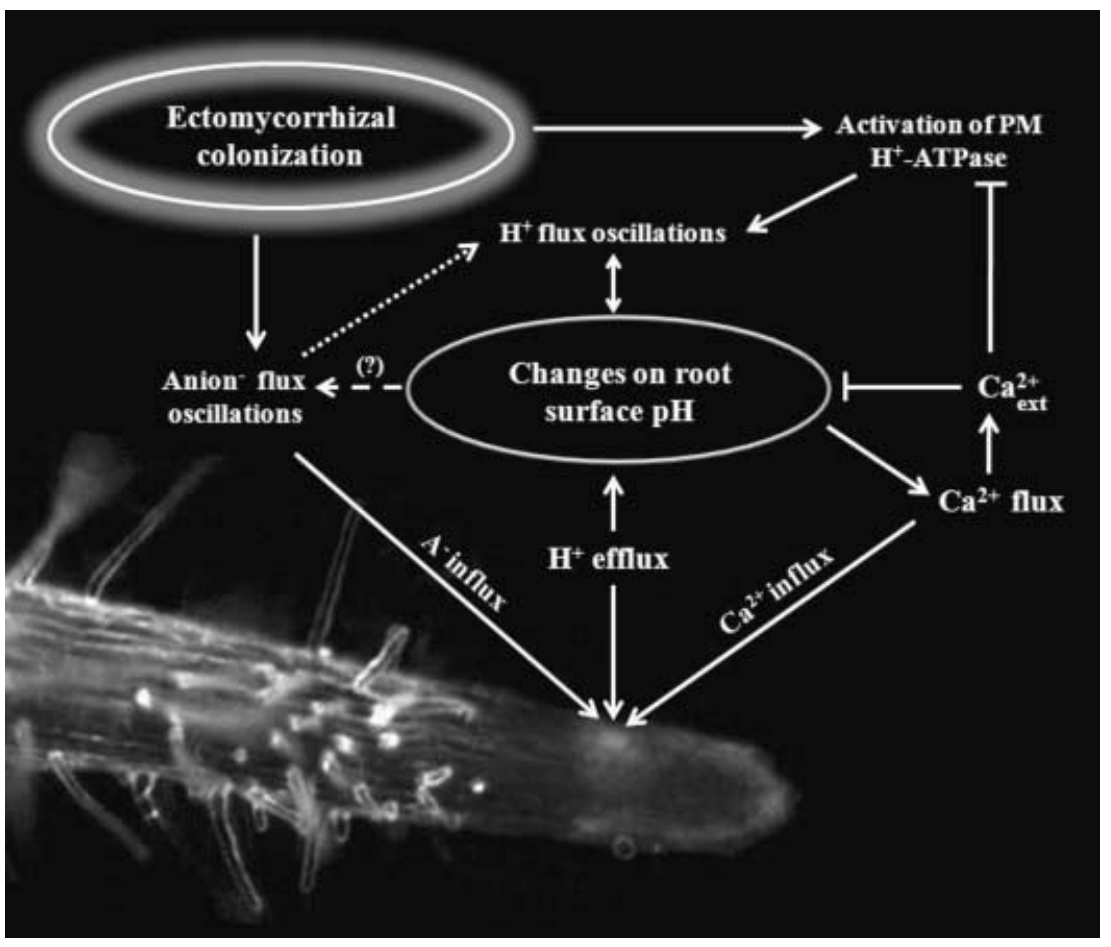

possible molecular basis for this was recently discovered in the same type of hyphae, where Corratgé et al. (2007) cloned the HcTrk1 transporter from Hebeloma cylindrosporum, and demonstrated it to encode for a single-file pore channel that cotransports $\mathrm{Na}^{+}-\mathrm{K}^{+}$into the hyphae.

Pharmacological analyses suggested the presence of anion channels at the elongation zone, since the influxes were sensitive to DIDS. In guard cells, DIDS also inhibits anion uptake (Schroeder et al., 1993; Schwartz et al., 1995) similar to what was observed in this study (Table 3). Further studies should be focused on the proper discrimination of the specific anions involved on the observed response at the elongation zone of ECM roots.

\section{Concluding remarks}

Based on our results, we propose a model for $\mathrm{pH}$ signaling in ECM roots, which is directly linked to nutrient uptake and plant growth (Table 2, Fig. 7). ECM fungi induce positive modulation of the $\mathrm{H}^{+}$efflux rates and rhizosphere acidification, mediated by PM H${ }^{+}$-ATPase activities from both host and fungal partners. In turn, this stimulation triggers a $\mathrm{pH}$ signal that modulates $\mathrm{Ca}^{2+}$ transport and, indirectly, anion uptake (Hedrich et al., 1990). This hypothesis is supported by our observation that external $\mathrm{Ca}^{2+}$ acts as a strong inhibitor of the $\mathrm{H}^{+}$efflux and root surface acidification in the elongation zone of eucalypt roots. By contrast, $\mathrm{Ca}^{2+}$ fluxes were also affected by the medium's $\mathrm{pH}$, as has previously been reported in other plant cells (Foster, 1990). An increase in anion uptake and lower concentrations of external $\mathrm{Ca}^{2+}$ will thus occur, which are reflected both in the promotion of plant growth and in $\mathrm{PM} \mathrm{H}^{+}$-ATPase activity (Zimmermann et al., 1994). The spectral analysis of the ion flux oscillations revealed itself to be an efficient parameter to compare biophysical effects of the ECM fungus in the fast oscillation components. This analysis can be used as an additional tool during the study of ion dynamics using the ion-selective vibrating probe technique, on the assumption that shifts in the main components of oscillations correspond to the activation/shift of a variety of molecular transporters.

\section{Acknowledgements}

We would like to acknowledge Prof. Michael Parkhouse and Dr Mark Seldon for their critical review of and helpful suggestions about the manuscript. This work was supported by a FCT PostDoc fellowship (SFRH/BPD/21061/2004) to ACR. JAF's laboratory is supported by FCT grants POCTI/BIABCM/61270/2004 and POCTI/BIA-BCM/60046/2004.

\section{References}

Ahonen-Jonnarth U, Van Hees PAW, Lundstrom US, Finlay RD. 2000. Organic acids produced by mycorrhizal Pinus sylvestris exposed to elevated aluminium and heavy metal concentrations. New Phytologist 146: 557-567.

Allen GJ, Sanders D. 1994. Two voltage-gated calcium release channels coreside in the vacuolar membrane of guard cells. Plant Cell 6: 685-694. 
Antoine AF, Faure JE, Cordeiro S, Dumas C, Rougier M, Feijó JA. 2000. A calcium influx is triggered and propagates as a wavefront in the zygote after in vitro fertilization of flowering plants. Proceedings of the National Academy of Sciences, USA 97: 10643-10648.

Antoine AF, Faure JE, Dumas C, Feijó JA. 2001. Differential contributions of free cytosolic and extracellular fluxes of calcium to gamete fusion and egg activation in flowering plants. Nature-Cell Biology 3: $1120-1124$.

Assmann SM, Simoncini L, Schroeder JI. 1985. Blue light activates electrogenic ion pumping in guard cell protoplasts of Vicia faba. Nature 318: 285-287.

Béguiristain T, Lapeyrie F. 1997. Host plant stimulates hypaphorine accumulation in Pisolithus tinctorius hyphae during ectomycorrhizal infection while excreted fungal hypaphorine controls root hair development. New Phytologist 136: 525-532.

Boukcim H, Plassard C. 2003. Juvenile nitrogen uptake capacities and root architecture of two open-pollinated families of Picea abies. Effects of nitrogen source and ectomycorrhizal symbiosis. Journal of Plant Physiology 10: 1211-1218.

Bowman BJ. 1982. Vanadate uptake in Neurospora crassa occurs via phosphate transport system II. Journal of Bacteriology 153: 286-291.

Bowman BJ, Allen KE, Slayman CW. 1983. Vanadate-resistant mutants of Neurospora crassa are deficient in a high-affinity phosphate transport system. Journal of Bacteriology 153: 292-296.

Brundrett M, Bougher NM, Dell B, Grove T, Malajczuck N. 1996. Working with mycorrhizas in forestry and agriculture. Camberra, Australia: Pirie Printers.

Bücking H, Hans R, Heyser W. 2007. The apoplast of ectomycorrhizal roots - site of nutrient uptake and nutrient exchange between the symbiotic partners. In: Sattelmacher B, Horst WJ, eds. The apoplast of higher plants: compartment of storage, transport and reactions. Dordrecht, the Netherlands: Springer-Verlag, 97-108.

Bücking H, Heyser W. 2000. Subcellular compartmentation of elements in nonmycorrhizal and mycorrhizal roots of Pinus sylvestris: an X-ray microanalytical study. II. The distribution of calcium, potassium and sodium. New Phytologist 145: 321-331.

Bücking H, Kuhn AJ, Schröder WH, Heyser W. 2002. The fungal sheath of ectomycorrhizal pine roots: an apoplastic barrier for the entry of calcium, magnesium, and potassium into the root cortex? Journal of Experimental Botany 53: 1659-1669.

Caldwell RA, Clemo HF, Baumgarten CM. 1998. Using gadolinium to identify stretch-activated channels: technical considerations. American Journal of Physiology - Cell Physiology 275: 619-621.

Churchill KA, Holaway B, Sze H. 1983. Separation of two types of electrogenic $\mathrm{H}^{+}$-pumping ATPases from oat roots. Plant Physiology 73 921-928.

Churchill KA, Sze H. 1984. Anion-sensitive, $\mathrm{H}^{+}$pumping ATPase of oat roots: direct effects of $\mathrm{Cl}^{-}, \mathrm{NO}_{3}^{-}$and a disulfonic stilbene. Plant Physiology 76: 490-497.

Clark RB. 1975. Characterization of phosphatase of intact maize roots. Journal of Agricultural and Food Chemistry 23: 458-460.

Corratgé C, Zimmermann S, Lambilliotte R, Plassard C, Marmeisse R, Thibaud JB, Lacombe B, Sentenac H. 2007. Molecular and functional characterization of a $\mathrm{Na}^{+}-\mathrm{K}^{+}$transporter from the Trk family in the ectomycorrhizal fungus Hebeloma cylindrosporum. Journal of Biological Chemistry. 282: 26057-26066.

Courty PE, Pouysegur R, Buee M, Garbaye J. 2006. Laccase and phosphatase activities of the dominant ectomycorrhizal types in a lowland oak forest. Soil Biology \& Biochemistry 38: 1219-1222.

Crawford NM. 1995. Nitrate: nutrient and signal for plant growth. Plant Cell 7: 859-868.

Dauphin A, Gérard J, Lapeyrie F, Legué V. 2007. Fungal hypaphorine reduces growth and induces cytosolic calcium increase in root hairs of Eucalyptus globulus. Protoplasma 231: 83-88.
Enriquez-Arredondo C, Sanchez-Nieto S, Rendon-Huerta E, Gonzalez-Halphen D, Gavilanes-Ruiz M, Diaz-Pontones D. 2005. The plasma membrane $\mathrm{H}^{+}$-ATPase of maize embryos localizes in regions that are critical during the onset of germination. Plant Science 169: 11-19.

Evans ML, Mulkey TJ, Vesper MJ. 1980. Auxin action on proton influx in corn roots and its correlation with growth. Planta 148: 510-512.

Feijó JA, Sainhas J, Hackett GR, Kunkel JG, Hepler PK. 1999. Growing pollen tubes posses a constitutive alkaline band in the clear zone and a growth-dependent acidic tip. Journal of Cell Biology 144: 483-496.

Felle HH. 2001. pH: signal and messenger in plant cells. Plant Biology 3: 577-591.

Ferrol N, Pozo MJ, Antelo M, Azcón-Aguilar C. 2002. Arbuscular mycorrhizal symbiosis regulates plasma membrane $\mathrm{H}^{+}$-ATPase gene expression in tomato plants. Journal of Experimental Botany 53 1683-1687.

Forde BG. 2000. Nitrate transporters in plants: structure, function and regulation. Biochimica et Biophysica Acta 1465: 219-235.

Foster JF. 1990. Influence of $\mathrm{pH}$ and plant nutrient status on ion fluxes between tomato plants and simulated acid mists. New Phytologist 116: 475-485.

Garnett TP, Shabala SN, Smethurst PJ, Newman IA. 2001. Kinetics of ammonium and nitrate uptake by eucalypt roots and associated proton fluxes measured using ion selective microelectrodes. Functional Plant Biology 30: 1165-1176.

Garnett TP, Shabala SN, Smethurst PJ, Newman IA. 2003. Simultaneous measurement of ammonium, nitrate and proton fluxes along the length of eucalypt roots. Plant and Soil 236: 55-62.

Garnett TP, Smethurst PJ. 1999. Ammonium and nitrate uptake by Eucalyptus nitens: effects of $\mathrm{pH}$ and temperature. Plant and Soil 214: 133-140.

Glass AD, Shaff JE, Kochian LV. 1992. Studies of the uptake of nitrate in barley. IV. Electrophysiology. Plant Physiology 99: 456-463.

Gobert A, Plassard C. 2002. Differential $\mathrm{NO}_{3}^{-}$dependent patterns of $\mathrm{NO}_{3}^{-}$ uptake in Pinus pinaster, Rhizopogon roseolus and their ectomycorrhizal association. New Phytologist 154: 509-516.

Hager A. 2003. Role of the plasma membrane $\mathrm{H}^{+}$-ATPase in auxin induced elongation growth. Historical and new aspects. Journal of Plant Research 116: 483-505.

Hawkins BJ, Boukcim H, Plassard C. 2008. A comparison of ammonium, nitrate and proton net fluxes along seedling roots of Douglas-fir and lodgepole pine grown and measured with different inorganic nitrogen sources. Plant, Cell \& Environment 31: 278-287.

Hedrich R, Busch H, Raschke K. 1990. $\mathrm{Ca}^{2+}$ and nucleotide dependent regulation of voltage dependent anion channels in the plasma membrane of guard cells. EMBO Journal 9: 3889-3892.

Ihaka R, Gentleman R. 1996. R: a language for data analysis and graphics. Journal of Computational and Graphical Statistics 5: 299-314.

Jahn T, Baluska F, Michalke W, Harper JF, Volkmann D. 1998. Plasma membrane $\mathrm{H}^{+}$-ATPase in the root apex: evidence for strong expression in xylem parenchyma and asymmetric localization within cortical and epidermal cells. Physiologia Plantarum 104: 311-316.

Javelle A, Andre B, Marini AM, Chalot M. 2003. High-affinity ammonium transporters and nitrogen sensing in mycorrhizas. Trends in Microbiology 11: 53-55.

Klüsener B, Boheim G, Liss H, Engelberth J, Weiler EW. 1995. Gadolinium-sensitive, voltage-dependent calcium release channels in the endoplasmic reticulum of a higher plant mechanoreceptor organ. $E M B O$ Journal 14: 2708-2714.

Knight H, Trewavas AJ, Knight MR. 1996. Cold calcium signaling in Arabidopsis involves two cellular pools and a change in calcium signature after acclimation. Plant Cell 8: 489-50.

Kochian LV, Shaff JE, Kühtreiber WM, Jaffe LF. 1992. Use of an extracellular, ion-selective, vibrating microelectrodes system fort the 
quantification of $\mathrm{K}^{+}, \mathrm{H}^{+}$and $\mathrm{Ca}^{2+}$ fluxes in maize suspension cells. Planta 188: 601-610.

Kuhn AJ, Schröder WH, Bauch J. 2000. The kinetics of calcium and magnesium entry into mycorrhizal spruce roots. Planta 210: 488-96.

Kunkel JG, Cordeiro S, Xu J, Shipley AM, Feijó JA. 2006. The use of noninvasive ion-selective microelectrode techniques for the study of plant development. In: Volkov V, ed. Plant electrophysiology-theory and methods. Berlin, Germany: Springer-Verlag, 109-137.

Lecourieux D, Ranjeva R, Pugin A. 2006. Calcium in plant defencesignalling pathways. New Phytologist 171: 249-69.

Lei J, Dexheimer J. 1988. Ultrastructural localization of ATPase activity in the Pinus sylvestris/Laccaria laccata ectomycorrhizal association. New Phytologist 108: 329-334.

Lino B, Baizabal-Aguirre VM, González de la Vara LE. 1998. The plasma membrane $\mathrm{H}^{+}$-ATPase from beet root is inhibited by a calcium-dependent phosphorylation. Planta 204: 352-359.

Malajczuk N, Cromack K Jr. 1982. Accumulation of calcium oxalate in the mantle of ectomycorrhizal roots of Pinus radiata and Eucalyptus marginata. New Phytologist 92: 527-531.

Marchner H, Dell B. 1994. Nutrient uptake in mycorhizal symbiosis. Plant and Soil 159: 89-102.

Martin F, Aerts A, Ahrén D, Brun A, Danchin EGJ, Duchaussoy F, Gibon J, Kohler A, Lindquist E, Pereda V et al. 2008. The genome of Laccaria bicolor provides insights into mycorrhizal symbiosis. Nature 452: 88-92.

Martin F, Kohler A, Duplessis S. 2007. Living in harmony in the wood underground: ectomycorrhizal genomics. Current Opinion in Plant Biology 10: 204-210.

Marx DH. 1969. The influence of ectotrophic mycorrhizal fungi on the resistance of pine roots to pathogenic fungi and soil bacteria. I. Antagonism of mycorrhizal fungi to root pathogenic fungi and soil bacteria. Phytopathology 59: 153-163.

Messerli MA, Smith PJS, Lewis RC, Robinson KR. 2004. Chloride fluxes in lily pollen tubes: a critical reevaluation. Plant Journal 40: 799-812.

Michard E, Dias P, Feijó JA. 2008. Tobacco pollen tubes as cellular models for ion dynamics: improved spatial and temporal resolution of extracellular flux and free cytosolic concentration of calcium and protons using pHluorin and YC3.1 CaMeleon. Sexual Plant Reproduction 21: 169-181.

Moloney MM, Elliott MC, Cleland RE. 1981. Acid growth effects in maize roots: evidence for a link between auxin economy and proton extrusion in the control of root growth. Planta 152: 285-291.

Müller T, Avolioa M, Olivia M, Benjdiab M, Rikirschb E, Kasarasa A, Fitza M, Chalotc M, Wipfa D. 2007. Nitrogen transport in the ectomycorrhiza association: the Hebeloma cylindrosporum-Pinus pinaster model. Phytochemistry 68: 41-51.

Nemchinov LG, Shabala L, Shabala S. 2008. Calcium efflux as a component of the hypersensitive response of Nicotiana benthamiana to Pseudomonas syringae. Plant and Cell Physiology 49: 40-46.

Palmgren MG. 2001. Plant plasma membrane $\mathrm{H}^{+}$-ATPases: powerhouses for nutrient uptake. Annual Review of Plant Physiology and Plant Molecular Biology 52: 817-845.

Parker DR, Chaney RL, Norvell WA. 1995. Chemical equilibrium models: applications to plant nutrition research. In: RH Loeppert, AP Schwab, S Goldberg, eds. Chemical equilibrium and reaction models. Madison, WI, USA: Soil Science Society of America, Inc, 163-200, 253-269.

Pasqualini S, Panara F, Antonielli M. 1992. Acid-phosphatase-activity in Pinus-pinea-Tuber-albidum ectomycorrhizal association. Canadian Journal of Botany 70: 1377-1383.

Peterson CA, Enstone DE. 1996. Functions of passage cells in the endodermis and exodermis of roots. Physiologia Plantarum 97: 592-598.

Plassard C, Guérin-Laguette A, Véry AA, Casarin V, Thibaud JB. 2002. Local measurements of nitrate and potassium fluxes along roots of maritime pine. Effects of ectomycorrhizal symbiosis. Plant, Cell \& Environment 25: 75-84.
Portillo F. 2000. Regulation of plasma membrane $\mathrm{H}^{+}$-ATPase in fungi and plants. Biochimica et Biophysica Acta 1469: 31-42.

Ramos AC, Façanha AR, Feijó JA. 2008a. Proton $\left(\mathrm{H}^{+}\right)$flux signature for the presymbiotic development of the arbuscular mycorrhizal fungi. New Phytologist 178: 177-188.

Ramos AC, Façanha AR, Feijó JA. 2008b. Ion dynamics during the polarized growth of arbuscular mycorrhizal fungi: from presymbiosis to symbiosis. In: Varma A, ed. Mycorrhiza: structure function and biotechnology. Heidelberg, Germany: Springer-Verlag, 241-261.

Ramos AC, Martins MA, Façanha AR. 2005. ATPase and pyrophosphatase activities in corn root microsomes colonized with arbuscular mycorrhizal fungi. Brazilian Journal of Soil Science 29: 207-213.

Rayle DL, Cleland RE. 1992. The acid growth theory of auxin-induced cell elongation is alive and well. Plant Physiology 99: 1271-1274.

Rosewarne GM, Smith FA, Schachtman DP, Smith SE. 2007. Localization of proton-ATPase genes expressed in arbuscular mycorrhizal tomato plants. Mycorrhiza 17: 249-258.

Rygiewicz PT, Bledsoe CS. 1984. Mycorrhizal effects on potassium fluxes by northwest coniferous seedlings. Plant Physiology 76: 918-923.

van Scholl L, Hoffland E, van Breemen N. 2006. Organic anion exudation by ectomycorrhizal fungi and Pinus sylvestris in response to nutrient deficiencies. New Phytologist 170: 153-163.

Schroeder JI, Schmidt C, Sheaffer J. 1993. Identification of high-affinity slow anion channel blockers and evidence for stomatal regulation by slow anion channels in guard cells. Plant Cell 5: 1831-1841.

Schwartz A, Ilan N, Schwarz M, Scheaffer J, Assmann SM, Schroeder JI. 1995. Anion-channel blockers inhibit S-type anion channels and abscisic-acid responses in guard cells. Plant Physiology 109: 651-658.

Shabala S, Newman IA. 2000. Salinity effects on the activity of plasma membrane $\mathrm{H}^{+}$and $\mathrm{Ca}^{2+}$ transporters in bean leaf mesophyll: masking role of the cell wall. Annals of Botany 85: 681-686.

Shipley AM, Feijó JA. 1999. The use of the vibrating probe technique to study steady extracellular currents during pollen germination and tube growth. In: Cresti M, Cai G, Moscatelli S, eds. Fertilization in higher plants: molecular and cytological aspects. Heidelberg, Germany: SpringerVerlag, 235-252.

Taylor JH, Peterson CA. 2005. Ectomycorrhizal impacts on nutrient uptake pathways in woody roots. New Forests 30: 203-214.

Tazawa M. 2003. Cell physiological aspects of the plasma membrane electrogenic $\mathrm{H}^{+}$pump, Journal of Plant Research 116: 419-442.

Ullrich CI, Novacky AJ. 1990. Extra- and intracellular $\mathrm{pH}$ and membrane potential changes induced by $\mathrm{K}^{+}, \mathrm{CI}^{-}, \mathrm{H}_{2} \mathrm{PO}_{4}^{-}, \mathrm{NO}_{3}^{-}$uptake and fusicoccin in root hairs of Limnobium storoniferum. Plant Physiology 94: 1561-1567.

Vieira L, Slotki I, Cabantchik ZI. 1995. Chloride conductive pathways which support electrogenic $\mathrm{H}^{+}$pumping by Leishmania major Promastigotes. Journal of Biological Chemistry 270: 5299-5304.

Ward JT, Lahner B, Yakubova E, Salt DE, Raghothama KG. 2008. The effect of iron on the primary root elongation of Arabidopsis during phosphate deficiency. Plant Physiology 147: 1181-1191.

Winch S, Pritchard J. 1999. Acid-induced cell wall loosening is confined to the accelerating region of the root growing zone. Journal of Experimental Botany 50: 1481-1487.

Yang X-C, Sachs F. 1989. Block of stretch-activated ion channels in Xenopus oocytes by gadolinium and calcium ions. Science. 243: 1068-1071.

Zimmermann S, Thomine S, Guern J, Barbier-Brygoo H. 1994. An anion current at the plasma membrane of tobacco protoplasts shows ATP-dependent voltage regulation and is modulated by auxin. Plant Journal 6: 707-716.

Zonia L, Cordeiro S, Feijó JA. 2001. Ion dynamics and the control of hydrodynamics in the regulation of pollen tube growth. Sexual Plant Reproduction 14: 111-116.

Zonia L, Cordeiro S, Tupy J, Feijó JA. 2002. Oscillatory chloride efflux at the pollen tube apical tip has a role in growth and osmoregulation and is linked to inositol polyphosphate signaling pathways. Plant Cell 14: 2233-2249. 


\section{Supporting Information}

Additional supporting information may be found in the online version of this article.

Fig. $\mathbf{S 1}$ Fourier frequency spectrum analysis of $\mathrm{H}^{+}(\mathrm{a}, \mathrm{b})$, $\mathrm{Ca}^{2+}(\mathrm{c}, \mathrm{d})$ and anion flux oscillations in the elongation zone of nonmycorrhizal (a, c, e) and mycorrhizal roots (ECM) of Eucalyptus globulus colonized by Pisolithus microcarpus (b, d, f).

Fig. S2 $\mathrm{H}^{+}, \mathrm{Ca}^{2+}$ and $\mathrm{Cl}^{-}$(anion) fluxes (a, b, c) of the Clark solution without any biological material (Reference) and their respective Fourier analysis (d, e, f).
Fig. S3 (a) Interference on $\mathrm{Cl}^{-}$activity detection by the $\mathrm{Cl}^{-}$electrode (control) by further anions $\left(\mathrm{NO}_{3}^{-}, \mathrm{SO}_{4}^{2-}\right.$ and $\mathrm{PO}_{4}^{2-}$ ) present in quarter-strength Clark solution. (b) Calibration of $\mathrm{Cl}^{-}$electrodes with different anions.

Fig. S4 Effect of different concentrations of gadolinium $\left(\mathrm{Gd}^{3+}\right)$ on the sensitivity of $\mathrm{Ca}^{2+}$ electrodes $(n=5)$.

Please note: Wiley-Blackwell are not responsible for the content or functionality of any supporting information supplied by the authors. Any queries (other than missing material) should be directed to the New Phytologist Central Office.

\section{Pbout New Phytologist}

- New Phytologist is owned by a non-profit-making charitable trust dedicated to the promotion of plant science, facilitating projects from symposia to open access for our Tansley reviews. Complete information is available at www.newphytologist.org.

- Regular papers, Letters, Research reviews, Rapid reports and both Modelling/Theory and Methods papers are encouraged. We are committed to rapid processing, from online submission through to publication 'as-ready' via Early View - our average submission to decision time is just 29 days. Online-only colour is free, and essential print colour costs will be met if necessary. We also provide 25 offprints as well as a PDF for each article.

- For online summaries and ToC alerts, go to the website and click on 'Journal online'. You can take out a personal subscription to the journal for a fraction of the institutional price. Rates start at $£ 139$ in Europe/\$259 in the USA \& Canada for the online edition (click on 'Subscribe' at the website).

- If you have any questions, do get in touch with Central Office (newphytol@lancaster.ac.uk; tel +44 1524 594691) or, for a local contact in North America, the US Office (newphytol@ornl.gov; tel +1 865576 5261). 